\title{
Teaching Practice of News English Listening Based on Digital Resources
}

\author{
Huiying Xie
}

\author{
Department of Foreign Languages, City College of Dongguan University of Technology, Dongguan, \\ Guangdong, China, 523419 \\ flsxhy@163.com
}

Keywords: News English listening; digital resources; online class; traditional class

\begin{abstract}
The uniqueness of News English listening makes it become the most difficult part in English listening teaching. In view of the problems of teaching in our country, such as short teaching hours, plentiful teaching contents, single teaching mode and poor teaching effects, the author develops digital resources for News English to construct an online class, leading to an effective mode of blended teaching combining the advantages of network class and of traditional class. Practice proves that the students in the experimental class have surpassed those in the control class after a semester of learning in terms of vocabulary, news lead, grasp of the six elements as well as news retelling. This teaching mode has promoted the teaching reform of the News English listening, effectively improving the teaching efficiency and greatly increasing the student's learning autonomy.
\end{abstract}

\section{Introduction}

Listening comprehension requires learners to decode and respond to the input language through sounds, vocabulary, syntax and cultural background knowledge. Therefore, listening is a skill reflecting a learner's comprehensive English ability. One's listening level directly affects his/her speaking, reading and writing abilities. However, the traditional English education in our country focuses on the training of vocabulary and grammar, reading comprehension and writing abilities, but neglects the importance of English listening training. At present, the listening level of English learners is basically lower than that of grammar and reading. Therefore, in the CET/TEM examination where the proportion of listening scores is constantly increasing, the students often succeed in or fail because of their listening ability. Due to lack of training for a long time, even majors have difficulty raising their listening levels within a short time after admission into the university. Listening is still a relatively weak one among the basic skills of English majors.

The author made a random questionnaire survey on the sophomore English majors of this university, and a total of 144 effective questionnaires were collected. The results show that 59.72\% of the students think that listening is the most difficult one in the five basic skills including listening, speaking, reading, writing and translation, but only $4.86 \%$ keep on listening practice every day, and $54.17 \%$ once or twice a week. Among the students, $48.61 \%$ think that News English listening is the most difficult whether in class or in daily life; $50.69 \%$ say that they cannot understand the news English by listening without reading the original text in advance, and 34.03\% cannot understand the listening content until it is repeated for three times. In this paper, therefore, an empirical research is conducted to study the effects of the in-class and after-class blended teaching mode on the improvement of the students' listening level of News English by using the digital resources for News English learning in the online class. 


\section{Current Situation of Listening Teaching in English Majors}

Listening is a basic compulsory course for fresh and sophomore English majors, but most students do not have a significant increase in the listening level or the learning does not achieve the desired effect after two years of study. The problems in teaching classes, teaching contents, teaching methods and the students' learning attitudes result in passive teaching and poor effects.

(1) Plentiful Contents within Short Teaching Time. Only two listening classes are arranged per week, i.e. a total of 90 minutes. As required by the syllabus, the teaching contents should include pronunciation discrimination, conversation, passage, lecture, news and so on. In order to complete the teaching tasks, therefore, teachers train the students and track their actual learning situation less in class. If the student's listening training is only done in the classroom, it is obviously far from enough.

(2) Single Teaching Mode. At present, teachers mainly adopt the traditional listening teaching mode, namely using fixed textbook, repeating the audios and checking the answers. Monotonous teaching content and mode makes it difficult for students to concentrate in the class for a long time, and their enthusiasm of learning is affected as well.

(3) Less Learning Enthusiasm of Students. According to the questionnaire survey, $59.72 \%$ of the students believe that listening is the most difficult, but only $4.86 \%$ keep on the listening training themselves every day. On the one hand, it is difficult for students to quickly change from their passive learning model to the active learning model after admission into the university. On the other hand, the long-term anxiety and frustration in the traditional class have greatly reduced their learning enthusiasm. Listening checks a learner's English comprehensive ability, so the students should have good English basics to quickly record the relevant information and achieve effective output. However, the students at a lower level cannot understand the listening contents unless they translate what they heard into Chinese, which affects their speed to track the information, thus, failing to follow the teaching rhythm in class.

\section{Feasibility of Information-based Teaching in News English Listening}

News English has unique structure and language features, which makes it the most difficult part in the training of English listening. At present, the English listening teaching in China is carried out mainly in the traditional mode and has no strict requirements on the listening training, which is the result of the examination-oriented education. In order to complete the teaching tasks, teachers only train the students through extensive listening, and only 10-15 minutes is assigned to the news English listening per week. So, it is difficult to improve the students' listening level.

In recent years, with the rapid development of modern information, the online self-learning mode based on micro-courses, MOOC and audios has become a supplementary means of teaching. Teachers explore the knowledge system and develop the "granular" teaching digital resources according to their teaching objectives, course content and learning conditions in the course; and the online class is constructed by using such digital resources, effectively implementing the blended teaching mode in which the advantages of the online class are combined with those of the traditional class. This new model promotes the teaching reform of News English listening and improves the efficiency of teaching and learning.

(1) News English itself is in line with the requirements of "granular" knowledge. The time length of a piece of news is about 3-5 minutes, so the real time that the teacher decomposes the knowledge is saved, which is conductive for teachers to prepare the digital resources based on micro-course, 
audio, etc.

(2) The problem of insufficient teaching time is solved. Teachers assign tasks in the online class, and students will arrange self-learning after class according to their own level. On the one hand, the learning duration of the students extends from 15 minutes per week to more than 30 minutes per day; and on the other hand, the students at a lower level can complete the learning tasks by watching or listening to the teaching video many times, which greatly increases the learning time of such students.

(3) The single teaching model is changed. In this mode, it is avoided that teachers arrange a lot of extensive listening content in class in order to complete their teaching tasks. Teachers only need to supervise the students, inspire them to learn and provide feedback of their learning results, and then complete consolidation and internalization of knowledge in the traditional class. Therefore, the effective online and offline communication between teachers and students are achieved.

(4) The students' learning enthusiasm is improved. The students at a higher level can find their problems after completion of the tasks, and adjust their learning plan according to the feedback from the teacher, which greatly improves the learning efficiency. While the students at a lower level can learn and absorb the knowledge points anytime and anywhere by watching the teaching video or listening to audio repeatedly, which reduces their sense of anxiety and fear due to failure of following the teaching rhythm in class.

\section{Exploration on the Teaching Practice of News English Listening Based on Digital Resources}

\subsection{Analysis of Research Objects}

The author conducted a comparative analysis on the teaching effect on two classes of sophomore English majors in the first semester. The students' vocabulary is about 5,000 to 5,500. In the experimental class, there were a total of 48 students. The teacher adopted the online class and offline class blended teaching model, and urged the students to complete their learning tasks in the online class, and make a good preparation for the offline class. In the control class, there were a total of 46 students. The teacher adopted the traditional teaching model. In class, a 15-minute News English listening training was arranged. The teacher played the audio repeatedly and then check the answers.

\subsection{Construction of Digital Resources and Building of the Network Learning Platform}

The structure of News English includes three parts, i.e. lead, body and ending, covering six elements, namely 5W (who, when, where, what and why) and $1 \mathrm{H}$ (how). It generally adopts the flashback method, the inverted pyramid structure, where the most important information of the news is laid in the first sentence of the lead. The news lead highly summarizes the contents of the news. If learners can understand the lead by listening, then they basically understand the whole news. However, the frequent use of proper nouns, acronyms and minor terms in News English, together with the emergence of new words, greatly influence learners' listening comprehension.

According the questionnaire survey, the author finds that $86.81 \%$ of the students have no habit of listening or watching news every day, and only $13.19 \%$ can learn with the rich online resources after class. They also believe that vocabulary and background knowledge are the main factors affecting their listening comprehension. 52.78\% say that they cannot retell the news with their own words even if they have understood them. Therefore, the author constructed the digital resources and set up a network teaching platform for English news listening as follows, by combining the characteristics of English news and learning. 
(1) News English was divided into eight modules, including cultural life, education, people, nature, politics, military, economic and technology. The eight modules were arranged from the easiest one to the most difficult one, and the time length of each module was 2 weeks, totaling 16 weeks for the eight.

(2) In view of the timeliness of news, nearly five years of news were selected as the digital resources.

(3) Through the use of SPOC, an online class platform was built, and the teaching content includes micro-class, video, voice and rich-media resources.

(4) A piece of news is taken per day, and the learning content includes cultural background, related vocabulary, news content and self-test.

\subsection{Implementation of Teaching}

The author adopted the blended teaching mode by combining the online class with the offline class. At present, most of learners have a misunderstanding on English listening training, and they think that they can improve their listening level as long as keeping on listening. In fact, however, what they can understand by listening is just they have understood through reading. Therefore, the above-mentioned situation was taken into account in the construction of digital resources for online class, the author first prepared the micro-course to explain the background and the new words of the news, then started the News listening training, and finally asked the students to take the self-test.

In the online class, the students could complete their learning tasks according to their own level and learning demands every day. In the process of self-test, the students were required to complete two exercises: firstly, to understand the news lead and complete the exercises; and secondly, to find out the $5 \mathrm{~W}$ and $1 \mathrm{H}$ in the news and complete the relevant exercises. In addition, the teacher tracked the students' learning situation in the network platform, provided the timely feedback, summarized and analyzed the high-frequency errors, which is conducive to perform the concentrated guidance in the face-to-face traditional class, and adjusted the teaching difficult points and teaching methods.

In the offline class, namely traditional class, the teacher could make full use of the 15-minute that had been originally distributed to News English for consolidation and internalization of knowledge. First, the teacher concentrated on explaining the most mistakes in the training of the past week and gave constructive advice to the training of the next stage. Then, the teacher randomly selected some students to retell the news of the previous week without referring to the manuscript, and the other students listened carefully and made notes, preparing for the Q \& A link. This output pattern effectively checks the degree at which the students have grasped the training contents. Finally, the teacher randomly selected a student to make the follow-up report of a piece of news orally and the other students also prepare for the Q \& A link. This method has enabled students to expand their learning resources and deepen their study.

\section{Teaching Effect and Evaluation}

After a semester of News English teaching, the author conducted a comparative analysis on the listening levels of the two classes. The results show that the students' vocabulary of the experimental class have been greatly increased, while that of the control class is basically maintained at the original level. In addition, the author also conducted a test on their listening levels, and found there was a big difference in the level of understanding the news lead, grasp of the six elements and effective output. The specific results are as shown in Table 1. 
Table 1 Test Results of the Experimental Class and the Control Class

\begin{tabular}{|l|l|l|}
\hline \multicolumn{1}{|c|}{ Test content } & Experimental Class & \multicolumn{1}{|c|}{ Control Class } \\
\hline Understood the news lead & $89.58 \%$ & $56.52 \%$ \\
\hline $\begin{array}{l}\text { Wrote down the proper nouns and new } \\
\text { words in the news }\end{array}$ & $79.16 \%$ & $43.48 \%$ \\
\hline $\begin{array}{l}\text { Grasped the 5W and 1H contents of the } \\
\text { news }\end{array}$ & $81.25 \%$ & $47.78 \%$ \\
\hline Retold the news content in their own words & $87.5 \%$ & $47.83 \%$ \\
\hline
\end{tabular}

The test results show that the average level of the students' English listening in the experimental class has greatly exceeded that of the students in the control class. Most of the students in the control class say that they did not have any outward News English training after class, while in class, they often gave up part of training since they couldn't understand the listening content or follow up the audio speed, and had to wait for the teacher's answer.

In the experimental class, the students say that the new face-to-face-class teaching mode has greatly improved their learning enthusiasm, and they get more practice opportunities in class. Besides, the students with a good basics think that the online class is a supplementary teaching means, significantly meeting their learning needs, and they can obtain the teacher's feedback timely; under the guidance of the teacher, they can deepen the study, greatly improving the learning effectiveness. The students with poor basis say that the cultural background and the new words introduction prior to the news listening training can help them better understand the news content and increase their confidence; they can absorb the knowledge slowly based on their own speed through continuous and repeated study, thus reducing the sense of frustration and fear in class; and the most important thing is that they can prepare for the retelling and oral report tasks with time as much as possible, so as to show their best performance in class, which greatly enhances their learning enthusiasm.

In summary, the online class provides more learning resources and creates a learning atmosphere for students, thus achieving the personalized self-learning model and enhancing the communication between teachers and students. Practice has proved that the combination of the advantages of the online class and the traditional class has greatly promoted the teaching reform of English listening and improved the efficiency of teaching and learning.

\section{Conclusion}

The improvement of listening level is a gradual process, requiring students to have a strong learning autonomy, actively participate in class activities and timely check the effective output ability. The construction of digital teaching resources and the building of the network learning platform have changed the traditional English listening teaching mode and greatly increased the time and contents of teaching and learning so that students are completely trained. The combination of the advantages of the traditional class and the online class has changed the single teaching model of the traditional class, increasing the interest in the News English listening teaching and effectively improving the teaching effect. However, this teaching model has brought teachers a great challenge. It requires them not only to learn information technology, but also to complete doubly-increased workload. For the teachers who need to take both research and teaching into account, it is difficult 
to keep on this teaching mode.

\section{Acknowledgements}

This work was financially supported by 2017 Higher Education Teaching Reform Project of City College of Dongguan University of Technology, 2017yjjg007.

This work was also financially supported by 2015 Higher Education Teaching Reform Project of Education Department of Guangdong On How an Independent College Cultivate Practical Translation Talents, 2015GXJK192.

\section{References}

[1] Lv Lijing. On the Teaching Mode of College English Listening Course under the Circumstance of Multi-Mode[J]. Journal of Heilongjiang Vocational Institute of Ecological Engineering, March 2017.

[2] Su Ke. Application of Networked News English in High-Level Listening Teaching of English Majors[J]. Education Teaching Forum, August 2016.

[3] Wu Yan, Zhang Huiling. A Survey on Efficiency of English Major's Listening Teaching[J]. Journal of Xi'an International Studies University, November 2005.

[4] Zhang Yaqun. Investigation and Analysis of the Improvement Effect of News English on English Majors’ Self-Learning Ability[J]. Campus English, 2015. 